\title{
The effect of nitrogen content on the photosynthesis of Scots pine needles and shoots
}

\author{
H. Smolander ${ }^{1}$ and P. Oker-Blom ${ }^{2}$ \\ 1 The Finnish Forest Research Institute, Suonenjoki Research Station, SF-77600 Suonenjoki, and \\ 2 University of Helsinki, Department of Silviculture, Unioninkatu 40 B, SF-00170 Helsinki, Finland
}

\section{Introduction}

A close dependency between photosynthetic capacity and nitrogen content of leaves has been shown (e.g., DeJong, 1982). For coniferous trees, however, a large variation in the relationship has been found. It has been proposed that the reason for this could be that the nitrogen content, by affecting needle growth, changes the pattern of mutual shading within a shoot, which is the basic element used in studying photosynthesis of coniferous trees (Linder and Rook, 1984). The aim of this study was to analyze separately the effect of nitrogen content on the photosynthetic capacity of individual needles and on within-shoot shading. Needle photosynthesis was approximated by measuring the photosynthesis of 'thinned' shoots in a diffuse radiation field. Within-shoot shading was quantified in terms of the mean silhouette area to total needle area ratio of a shoot, which determines the relative interception rate per unit of needle area on the shoot (OkerBlom and Smolander, 1988).

\section{Materials and Methods}

One yr old experimental shoots were collected from 5 young Scots pine (Pinus sylvestris L.) stands in Suonenjoki $\left(62^{\circ} 39^{\prime} \mathrm{N}, 27^{\circ} 05^{\prime} \mathrm{E}\right)$ between 5 and 30 June 1988. The sites of the stands varied from poor sandy soil with Calluna vulgaris vegetation to a fertile site with grass-herb vegetation. A randomly selected shoot from the uppermost whorl of each tree was used in measurements of photosynthesis. Morphological characteristics and silhouette to total needle area ratios were measured for a shoot from the uppermost whorl and for 1st order and 2nd order shoots just below. The photosynthetic capacity of 10 shoots (2 trees/stand) and silhouette to total needle area ratio of 93 shoots ( 3 trees/stand) were measured.

The photosynthesis of excised shoots was measured in a diffuse radiation field using an open flow IRGA-system. In order to eliminate the effect of within-shoot shading, about twothirds of the needles on a shoot were removed the night before the day of measurement. The air temperature was $20^{\circ} \mathrm{C}$, external $\mathrm{CO}_{2}$ concentration was $340 \mathrm{ppm}$ and vapor pressure deficit 5-10 mbar in the chamber. The horizontal photon irradiance (measured by LI-190SR) was increased in an integrating sphere from 0 to $1000 \mu \mathrm{mol} \cdot \mathrm{m}^{-2} \cdot \mathrm{s}^{-1}$ in 7 or 8 steps and a steady state photosynthetic rate was obtained at each irradiance level. A non-rectangular hyper- 
bola was fitted to the measured photosyrithetic rates using the method of least squares and the value at $2000 \mu \mathrm{mol} \cdot \mathrm{m}^{-2} \cdot \mathrm{s}^{-1}$ was used as an estimate of the photosynthetic capacity.

The silhouette area of each shoot was measured photographically at 6 different inclinations of the shoot axis to the plane of projection. The effect of asymmetry of the shoot was eliminated by rolating the shoot 4 times in increments of $60^{\circ}$ for each inclination angle. The mean silhouette area with respect to a spherical shoot orientation was calculated as a weighted average of the 24 silhouette areas measured. The mean silhouette to total needle area ratio (STAR) was then obtained by dividing mean silhouette area by the total needle area of a shoot, which was approximated as $\pi$ times the projected needle area (measured by a LiCOR leaf area meter) Oker-Blom and Smolander, 1988).

Finally, needles were dried for $48 \mathrm{~h}$ at $80^{\circ} \mathrm{C}$ and their nitrogen content determined by the Central Laboratory of the Finnish Forest Research Institute using a LECO CHN-600 analyzer.

\section{Results and Discussion}

Despite the large variation in site fertility, the range of nitrogen concentration varied only from 0.49 to $1.5 \%$ of dry weight of needles. The low values of nitrogen

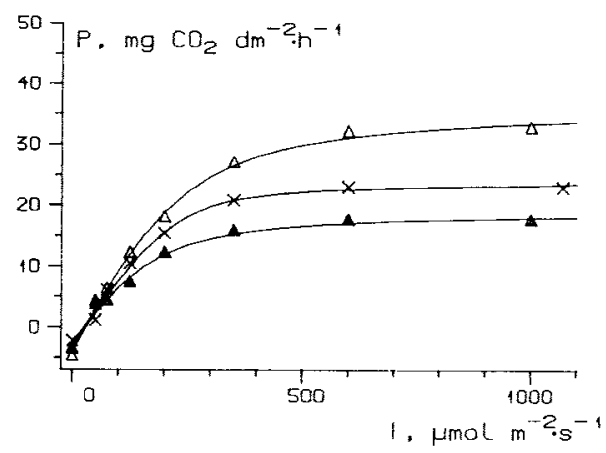

Fig. 1. Photosynthetic radiation response of 3 shoots of different nitrogen status: $1.48 \%(\Delta), 0.93 \%(x)$ and $0.77 \%(\mathbf{\Delta})$.

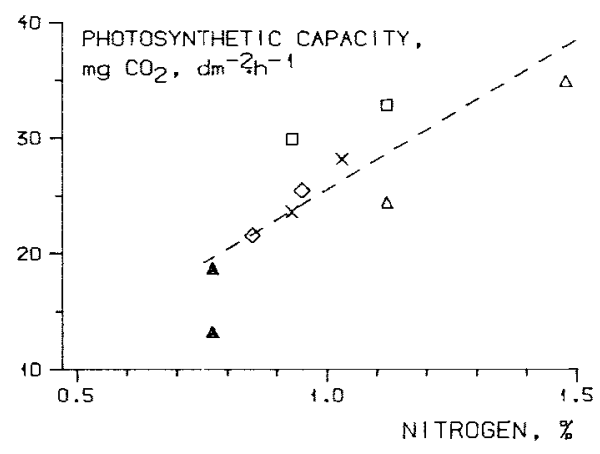

Fig. 2. Photosynthetic capacity as a function of nitrogen content. Symbols refer to different sites. $y=25.3 x$ $+0.1, R^{2}=0.62$.

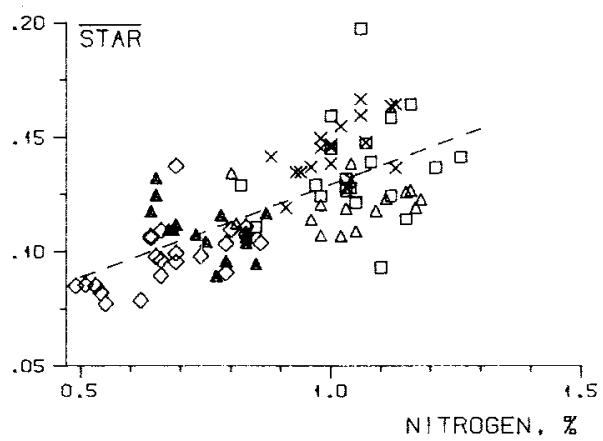

Fig. 3. The effect of nitrogen content on the $\overline{S T A R}-$ values of shoots. $y=0.081 x+0.049, R^{2}=0.44$

content are due to the fact that measurements were made during the growing phase of new shoots.

The photosynthetic radiation responses of the shoots measured in a diffuse radiation field were similar to those measured for single leaves (Fig. 1). The nitrogen content had a clear effect on the photosynthetic capacity of needles (Fig. 2). However, because of the narrow range of nitrogen content, the regression was not as close as is generally obtained for broadleaved trees. In this material, the nitrogen content explained $62 \%$ of the 


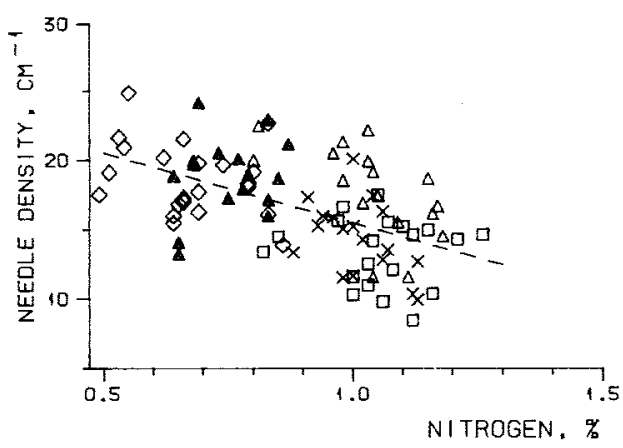

Fig. 4. Needle density on the shoot axis as a function of nitrogen content. $y=-10.0 x+25.6, R^{2}=0.28$.

variation in photosynthetic capacity, whereas coefficients of determination $>90 \%$ are typical for broadleaved trees.

The $\overline{S T A R}$-values of shoot were positively correlated to nitrogen contents (Fig. $3)$, contrary to what we had expected. Apparently, some changes in shoot structure eliminated the expected increase in mutual shading caused by enhanced needle growth. The STAR-value of a shoot is most sensitive to the needle density on the shoot axis and the angle between needle and shoot axis, while reedle length, for example, has a much smaller effect. In our material, the needle density decreased with increasing nitrogen content (Fig. 4) and the needle angle increased with increasing nitrogen content (Fig. 5).

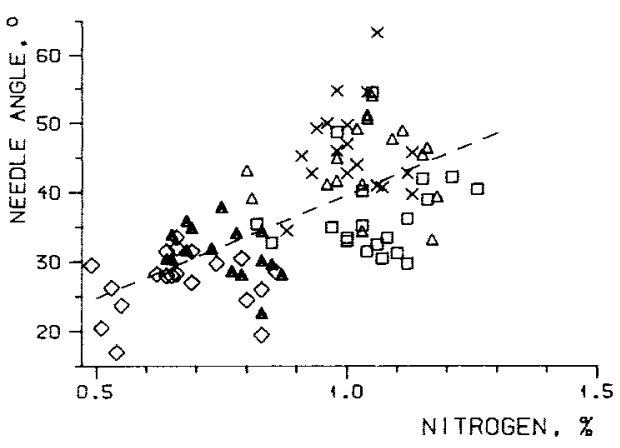

Fig. 5. Needle angle as a function of nitrogen content. $y=29.8 x+9.9, R^{2}=0.38$

In conclusion, nitrogen content can increase shoot photosynthesis in 2 ways: by increasing photosynthetic capacity of needles and by increasing light interception efficiency per unit area of needle surface on the shoot.

\section{References}

DeJong T.M. (1982) Leaf nitrogen content and $\mathrm{CO}_{2}$ assimilation capacity in peach. J. Am. Hortic. Sci. 107, 955-959

Linder S. \& Rook D.A. (1984) Effects of mineral nutrition on carbon dioxide exchange and partitioning of carbon in trees. In: Nutrition of Plantation Forests. (Bowen G.D. \& Nambiar E.K.S., eds.), Academic Press, London, pp. 211-236

Oker-Blom P. \& Smolander H. (1988) The ratio of shoot silhouette area to total needle area in Scots pine. For. Sci. 34, 894-906 